\title{
Palmar Fasciitis and Polyarthritis Associated with Gastric Carcinoma: Complete Resolution After Total Gastrectomy
}

\author{
Mami Enomoto, Hiroyuki Takemura, Motohiro Suzuki, Takamichi Yuhara, Takao Akama, \\ Kazuhide YAmANE and Takayuki SumIDA
}

\begin{abstract}
Palmar fasciitis and polyarthritis (PFA) is a rare paraneoplastic rheumatic syndrome characterized by flexion contractures of both hands and thickening of palmar fascia. Several reports have suggested that this syndrome is a tumor-associated autoimmune disorder. We report a 44-year-old Japanese man who presented with flexion contractures of both hands associated with thickening of palmar fascia and polyarthritis. These clinical pictures were suggestive of PFA associated with occult neoplasm. Upper gastrointestinal endoscopic examination revealed advanced gastric cancer. Resection of the cancer resulted in a gradual resolution of palmar fasciitis and polyarthritis. This clinical course suggests an underlying tumor-related immunologic process in this syndrome.
\end{abstract}

(Internal Medicine 39: 754-757, 2000)

Key words: musculoskeletal manifestation, paraneoplastic syndrome, malignant neoplasm

\section{Introduction}

Various musculoskeletal symptoms can be associated with neoplasms. Palmar fasciitis with polyarthritis (PFA) is a rare syndrome associated with neoplasm (1). The syndrome is characterized by rapidly progressive flexion contractures of both hands, nodular thickening of fascia of the palms and distal extremities, and polyarthritis. The exact etiology of PFA is not well understood, but a few reports have suggested that the syndrome might be the result of a tumor-associated autoimmune disease (1-3). We report herein a Japanese patient with gastric cancer who presented with PFA. Our case is of special interest in that the syndrome improved following surgical resection of the primary tumor. This clinical finding may lend support to the tumor-related immunopathological mechanism of this rare syndrome.
For editorial comment, see $\mathrm{p} 685$.

\section{Case Report}

A 44-year-old Japanese man presented in November 1997 with swelling and pain in both wrists. Treatment with nonsteroidal antiinflammatory drugs was unsuccessful, and pain gradually extended to involve all finger joints as well as other large joints. In January 1998, he noticed several nodular thickenings in the palms of both hands and painful restriction of finger movements. In May 1998, the patient was admitted to Tsukuba University Hospital for further evaluation of the reduced range of motion of his fingers and polyarthralgia. He had noted a $4 \mathrm{~kg}$ weight loss in the previous four months. The past medical history was negative for joint diseases, Raynaud's phenomenon and trauma.

Physical examination showed mild flexion contractures of all fingers with nodular subcutaneous thickenings in both palms, forearms, and legs (Fig. 1). The patient was unable to form a fist. Neither sclerodactyly nor nail fold capillary changes were noted. Mild arthritis was present in the shoulders, elbows, hands, hips, knees, and ankles. Neurological examination was negative.

Laboratory tests showed a normal complete blood cell count, Westergren erythrocyte sedimentation rate of $21 \mathrm{~mm} / 1 \mathrm{~h}, \mathrm{C}-$ reactive protein of $0.5 \mathrm{mg} / \mathrm{ml}$ (normal $<0.2$ ), and normal liver function tests except for a slightly elevated lactic dehydrogenase of $571 \mathrm{U} / l$ (normal <520). Renal function tests were normal. Immunological tests showed an antinuclear antibody titer of 1:80 with a speckled pattern, rheumatoid factor of $28 \mathrm{U} / \mathrm{ml}$ (normal <20), and soluble interleukin (IL)-2 receptor (sIL-2R) of $4,440 \mathrm{U} / \mathrm{ml}$ (normal $<530$ ). Joint radiographs were normal. Technetium- $99 \mathrm{~m}$ bone scan showed a slight increased uptake in both shoulders, wrists, hips, knees, and ankles.

A full-thickness skin biopsy was obtained from the left dorsal surface of the forearm because incision of the palmar fascia was thought to result in impairment of hand function. The bi-

From the Division of Rheumatology, Department of Internal Medicine, Institute of Clinical Medicine, University of Tsukuba, Ibaraki

Received for publication November 5, 1999; Accepted for publication February 21, 2000

Reprint requests should be addressed to Dr. Hiroyuki Takemura, the Division of Rheumatology, Department of Internal Medicine, Institute of Clinical Medicine, University of Tsukuba, 1-1-1 Tennodai, Tsukuba, Ibaraki 305-8575 


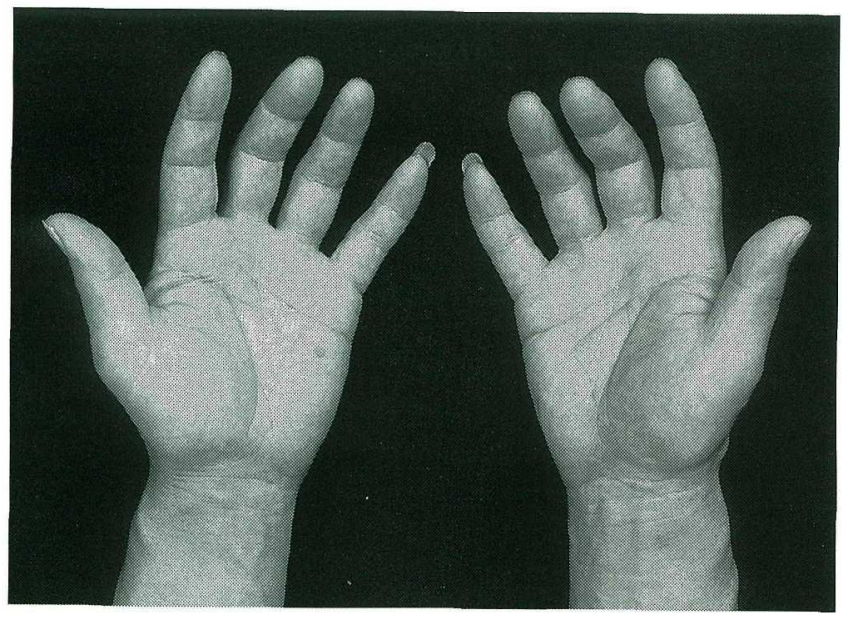

Figure 1. Anterior view of both hands. Note the mild contractures and arthritis affecting both hands.

opsy demonstrated mild thickening of the fascia with mononuclear inflammatory infiltrates (Fig. 2); eosinophils were rarely seen. Mild perivascular and periadnexal inflammatory cell infiltration was observed in the deep dermis.

These clinical and histological features were suggestive of "palmar fasciitis and polyarthritis associated with malignant neoplasms." Accordingly, we searched for an occult malignancy. Upper gastrointestinal endoscopic evaluation demonstrated an advanced IIa + IIc type tumor of the stomach. Biopsies revealed well-differentiated tubular adenocarcinoma. Computed tomography scans of the head, chest, and abdomen and bone scintigraphy were negative for metastasis or other malignancies. A final diagnosis of palmar fasciitis and polyarthritis with gastric cancer was established.

The patient underwent total gastrectomy. After curative resection of the tumor, the polyarthritis and nodular thickening of the palms, forearms, and lower legs showed a gradual spontaneous improvement. Serum sIL-2R level also decreased to $3,260 \mathrm{U} / \mathrm{ml}$.

\section{Discussion}

PFA is a rare syndrome associated with malignant neoplasms. To our knowledge, only a total of 19 publications describing 29 cancer patients with this syndrome have been reported in the English-language literature since the first case was described by Medsger et al in 1982 (4). Table 1 summarizes the published cases of PFA associated with malignancies. The most frequently reported malignancy associated with PFA is ovarian carcinoma (10 patients, $34 \%$ ), followed by neoplasms of the lung (2), breast (3), colon (5), and pancreas (6).

Clinical features of PFA are rapidly progressive flexion contractures of both hands and polyarthritis. There are no specific distinctive diagnostic tests for this disorder, and the diagnosis is therefore based on clinical presentation. The differen-

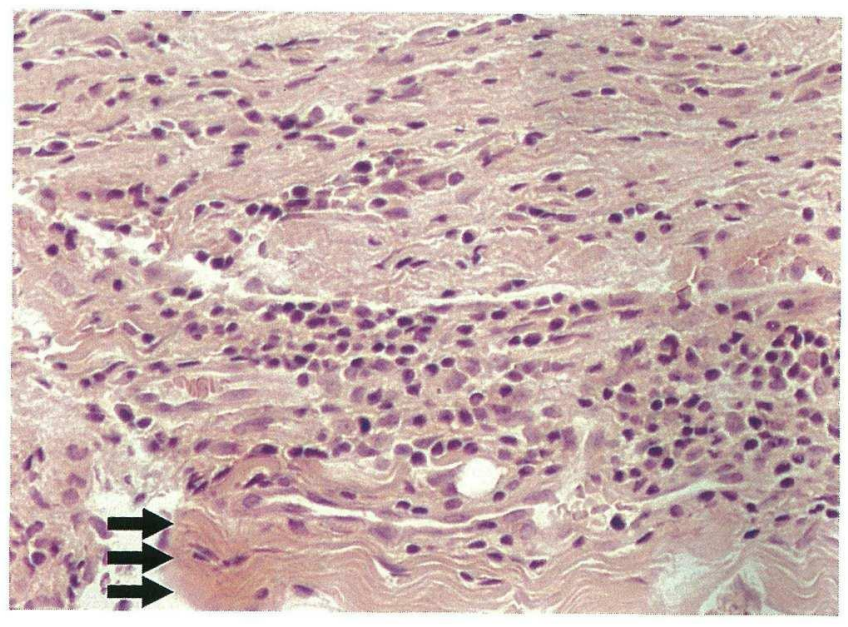

Figure 2. Histopathological findings of a full-thickness skin biopsy from the left dorsal surface of the forearm. Note the presence of mild thickening of the fascia (arrows) with mononuclear inflammatory infiltrates. The majority of inflammatory cells are lymphocytes with occasional plasma cells (HE stain, $\times 200$ ).

tial diagnosis includes other conditions associated with contractures of the hands. The musculoskeletal manifestations of PFA are similar to those of Dupuytren's contracture, an orthopedic disease of the hands. The latter causes flexion contractures of the fingers and nodular thickening of the palmar fascia (20). However, the findings of the present patient differed from the above disorder in that the thickening of the fascia extended to the forearms and lower legs and clinically apparent polyarthritis was present. Systemic sclerosis (SSc), a systemic fibrosing disorder, is often associated with contractures of the hands. However, Raynaud's phenomenon, seen in almost all patients with SSc, was not present in the present patient. The absence of skin sclerosis and esophageal dysfunction were two additional features against the diagnosis of SSc. Eosinophilic fasciitis is a rare fibrosing disease with a variable degree of eosinophilia (21). In this disorder, a symmetric and subcutaneous induration develops in the extremities, and some degree of joint contracture may occur. However, the hands are usually spared. The present patient had no eosinophilia. PFA could also resemble reflex sympathetic dystrophy (RSD), which is thought to be induced by reflex neurologic mechanisms. The clinical features of RSD include pain and swelling in the distal extremity, dystrophic skin changes, hand contractures, and vasomotor or sudomotor disturbances (22). PFA differs from RSD in that the fasciitis is more severe, arthritis is more inflammatory, and both processes are more rapidly progressive than in RSD (23). Furthermore, there are no vasomotor or sudomotor disturbances in PFA.

Several reports have suggested that PFA is the result of a tumor-associated, generalized autoimmune disorder $(7,13)$. Deposits of immunoglobulin and complements, mononuclear perivascular infiltrates, and fibrosis have been found in the fas- 
ENomoto et al

Table 1. Summary of Previously Published Cases of Palmar Fasciitis with Polyarthritis

\begin{tabular}{|c|c|c|c|c|}
\hline Author (Ref) & Year & $\begin{array}{l}\text { Age/ } \\
\text { Sex }\end{array}$ & Associated Malignancy & $\begin{array}{l}\text { Effect of Tx on Musculo- } \\
\text { skeletal manifestations }\end{array}$ \\
\hline \multirow[t]{5}{*}{ Medsger et al (4) } & 1982 & $65 / \mathrm{F}$ & Ovary & - \\
\hline & & $50 / \mathrm{F}$ & Ovary & - \\
\hline & & $62 / \mathrm{F}$ & Ovary & Improved with chemotherapy \& CS \\
\hline & & $58 / \mathrm{F}$ & Ovary & - \\
\hline & & $60 / \mathrm{F}$ & Ovary & Improved with chemotherapy \\
\hline Baron et al (5) & 1982 & $65 / \mathrm{F}$ & Bladder, Lung, Colon & Improved with CS \\
\hline Baer et al (6) & 1983 & $62 / \mathrm{F}$ & Pancreas & - \\
\hline \multirow[t]{2}{*}{ Shiel et al (2) } & 1985 & $86 / \mathrm{F}$ & Lung & - \\
\hline & & $75 / \mathrm{F}$ & Ovary & Improved with CS \\
\hline \multirow[t]{5}{*}{ Pfinsgraff et al (1) } & 1986 & $66 / \mathrm{F}$ & CML & Improved with CS \\
\hline & & $59 / \mathrm{F}$ & Pancreas & Improved with Penicillamine \\
\hline & & $66 / \mathrm{M}$ & SCC* & - \\
\hline & & $71 / \mathrm{F}$ & Adenocarcinoma* & - \\
\hline & & $54 / \mathrm{M}$ & Hodgkin & Improved with chemotherapy \\
\hline Valverde-Garcia et al (3) & 1987 & $55 / \mathrm{F}$ & Breast & Improved with chemotherapy \& CS \\
\hline Caron et al (7) & 1989 & $74 / \mathrm{F}$ & Plasmacytoma & - \\
\hline Zerbe et al (8) & 1991 & $54 / \mathrm{F}$ & Peritoneal carcinosis & Improved with chemotherapy \\
\hline Willemse et al (9) & 1991 & $54 / \mathrm{F}$ & Coelomic epithelial & Improved with CS \\
\hline Van den Bergh et al (10) & 1991 & $59 / \mathrm{M}$ & Prostate & - \\
\hline Strobel et al (11) & 1992 & $59 / \mathrm{F}$ & Ovary & Not mentioned \\
\hline Leslie (12) & 1992 & $55 / \mathrm{F}$ & Uterine cervix & - \\
\hline Vinker et al (13) & 1996 & $25 / \mathrm{F}$ & Ovary & - \\
\hline Dhôte et al (14) & 1997 & $66 / F$ & Breast & Improved with chemotherapy \\
\hline Saxman et al (15) & 1997 & $54 / \mathrm{F}$ & Breast & Not mentioned \\
\hline Wright (16) & 19.97 & $57 / \mathrm{F}$ & Ovary & Not mentioned \\
\hline \multirow[t]{2}{*}{ Grados et al (17) } & 1998 & $59 / \mathrm{F}$ & Renal pelvis & - \\
\hline & & $92 / \mathrm{F}$ & Uterine & - \\
\hline Eekhoff et al (18) & 1998 & $71 / \mathrm{M}$ & Large cell carcinoma* & Not mentioned \\
\hline Matteson (19) & 1998 & $69 / \mathrm{F}$ & Ovary & - \\
\hline Present case & 1999 & $44 / \mathrm{M}$ & Stomach & Improved after tumor resection \\
\hline
\end{tabular}

*Unknown primary, Tx: treatment, CS: corticosteroids, CML: chronic myelogenous leukemia, SCC: squamous cell carcinoma.

cia $(1-4,24)$. Antinuclear antibodies were positive in some cases $(1,2,4)$. One report has described the presence of leukocytoclastic vasculitis in the dermis (13). Interestingly, regression of fasciitis after antineoplastic treatment (Table 1) or excision of the tumor (24) has been reported. Likewise, the symptoms in the present patient gradually improved after resection of the tumor. Serum sIL-2R level, one of the markers of immune activation (25), also decreased in the present patient after tumor resection. These findings strongly suggest the involvement of tumor-related autoimmune mechanisms in the pathogenesis of PFA.

In summary, we have presented a Japanese patient in whom PFA syndrome was associated with gastric cancer. The present patient is unique in that the syndrome resolved after resection of the tumor, suggesting an underlying tumor-related immunologic process in this syndrome.

Acknowledgements: This study was supported in part by a grant from the University of Tsukuba Research Projects.

\section{References}

1) Pfinsgraff J, Buckingham RB, Killian PJ, et al. Palmar fasciitis and arthritis with malignant neoplasms: a paraneoplastic syndrome. Semin Arthritis Rheum 16: 118-125, 1986.

2) Shiel WC Jr, Prete PE, Jason M, Andrews BS. Palmar fasciitis and arthritis with ovarian and non-ovarian carcinomas. New syndrome. Am J Med 79: 640-644, 1985.

3) Valverde-Garcia J, Juanola-Roura X, Ruiz-Martin JM, Nolla-Sole JM, Rodriguez-Moreno J, Roig-Escofet D. Paraneoplastic palmar fasciitispolyarthritis syndrome associated with breast cancer. J Rheumatol 14: 1207-1209, 1987 (letter).

4) Medsger TA, Dixon JA, Garwood VF. Palmar fasciitis and polyarthritis associated with ovarian carcinoma. Ann Intern Med 96: 424-431, 1982.

5) Baron M. Palmar fasciitis, polyarthritis, and carcinoma. Ann Intern Med 97: 616, 1982 (letter).

6) Baer AN, Phillips RM Jr. Pancreatic carcinoma and palmar fasciitis. Ann Intern Med 99: 411-412, 1983 (letter).

7) Caron P, Lassoued S, Thibaut I, Fournie B, Fournie A. Thyroid plasmacytoma with dermatomyositis and palmar fasciitis. J Rheumatol 16: 997999, 1989. 


\section{Palmar Fasciitis and Polyarthritis}

8) Zerbe S, Blickle JF, Willemin B, Madon M, Brogard JM. Palmar fasciitis, a paraneoplastic manifestation: a new case. Eur J Int Med 2: 51-53, 1991.

9) Willemse PHB, Mulder NH, van de Tempel HJ, Aalders JG, Sleijfer DT. Palmar fasciitis and arthritis in a patient with an extraovarian adenocarcinoma of the coelomic epithelium. Ann Rheum Dis 50: 53-54, 1991.

10) Van den Bergh L, Vanneste SB, Knockaert DC. Palmar fasciitis and arthritis associated with cancer of the prostate. Acta Clin Belg 46: 106$110,1991$.

11) Strobel ES, Lacour M, Peter HH. Palmar fascial thickening and contractures of fingers resembling arthritis-a paraneoplastic symptom? Rheumatol Int 12: 79-80, 1992.

12) Leslie BM. Palmar fasciitis and polyarthritis associated with a malignant neoplasm: a paraneoplastic syndrome. Orthopedics 15: 1436-1439, 1992.

13) Vinker S, Dgani R, Lifschitz-Mercer B, Sthoeger ZM, Green L. Palmar fasciitis and polyarthritis associated with ovarian carcinoma in a young patient. A case report and review of the literature. Clin Rheumatol 15: 495-497, 1996.

14) Dhôte R, Beuzeboc P, Permal S, Poiraudeau S, Revel M, Christoforov B. Paraneoplastic palmar fasciitis and achalasia-like esophageal disorder in a patient with breast cancer. Rev Rheum Engl Ed 64: 350-352, 1997 (letter).

15) Saxman SB, Seitz D. Breast cancer associated with palmar fasciitis and arthritis. J Clin Oncol 15: 3515-3516, 1997.

16) Wright GD, Doherty M. Unusual and memorable. Ann Rheum Dis 56:
626, 1997.

17) Grados F, Houvenagel E, Cayrolle G, Bellony R, Fardellone P, Sebert JL. Two new cancer locations accompanied with palmar fasciitis and polyarthritis. Rev Rhum Engl Ed 65: 212-214, 1998.

18) Eekhoff EM, van der Lubbe PA, Breedveld FC. Flexion contractures associated with a malignant neoplasm: 'A paraneoplastic syndrome?' Clin Rheumatol 17: 157-159, 1998.

19) Matteson EL. Groove sign in paraneoplastic palmar fasciitis. J Rheumatol 25: 2043-2045, 1998 (letter).

20) Murrell GA. Scientific comment. Basic science of Dupuytren's disease. Ann Chir Main Memb Super 11: 355-361, 1992.

21) Wigley FM. Systemic sclerosis and related syndromes. in: Primer on the Rheumatic Diseases. 11th ed. Klippel JH Eds. Arthritis Foundation, Atlanta, 1997: 271.

22) Kozin F. Painful shoulder and the reflex sympathetic dystrophy syndrome. in: Arthritis and Allied Conditions. 13th ed. McCarty DJ Eds. Lea \& Febiger, Philadelphia, 1998: 1887-1922.

23) Naschitz JE, Rosner I, Rozenbaum M, Elias N, Yeshurun D. Cancer-associated rheumatic disorders: clues to occult neoplasia. Semin Arthritis Rheum 24: 231-241, 1995.

24) Champion GD, Saxon JA, Kossard S. The syndrome of palmar fibromatosis (fasciitis) and polyarthritis. J Rheumatol 14: 1196-1198, 1987.

25) Waldmann-TA. The interleukin-2 receptor. J-Biol-Chem 266: 2681-2684, 1991. 